\title{
Hope ensina e reforça representações: estratégias da publicidade para o corpo feminino
}

\author{
Hope teaches and reinforces representations: advertising strategies \\ for the female body
}

\section{Denise da Costa Oliveira Siqueira ${ }^{[a]}$, Vanessa de Moraes Ribeiro ${ }^{[b]}$}

\footnotetext{
[a] Doutora em Ciências da Comunicação pela Escola de Comunicações e Artes da Universidade de São Paulo (USP), pós-doutora em Sociologia no Centre détudes sur lactuel et le quotidien da Université Paris-Descartes/Sorbonne, França,e-mail: denisedacosta@ ig.com.br

[b] Mestranda em Comunicação pela Universidade do Estado do Rio de Janeiro (UERJ), MBA em Gestão da Comunicação Estratégica pelo Centro Universitário Vila Velha (UVV), coordenadora do Curso de Graduação em Comunicação Social - Publicidade e Propaganda da Universidade Veiga de Almeida (UVA), Cabo Frio, RJ-Brasil, e-mail: ribeiro.vanessa@gmail.com
}

\section{Resumo}

Neste artigo analisamos os desdobramentos da campanha publicitária "Hope ensina", estrelada pela modelo Gisele Bündchen para a marca de lingerie em setembro de 2011. Na campanha, a sensualidade da "mulher brasileira" é usada como recurso para amenizar más notícias. Criada pela agência Giovanni+DraftFCB, a campanha chamou a atenção da Secretaria de Políticas para as Mulheres, que solicitou ao Conar a suspensão da publicidade e manifestou ao anunciante seu repúdio à campanha. Em termos metodológicos, reunimos um anúncio e três comerciais que foram descritos e analisados à luz da leitura de Mauss, Goldenberg e Lipovetsky.

Palavras-chave: Corpo. Mulher. Publicidade. Hope. Conar.

\section{Abstract}

In this article we examine the ramifications of the advertising campaign "Hope ensina," starred by the top model Gisele Bündchen for lingerie brand in September 2011. In the campaign, the sensuality of the "Brazilian women" is used as a resource to soften bad news. Created by the agency Giovanni + DraftFCB, the campaign caused the 


\begin{abstract}
attention of the Secretariat of Policies for Women that requested the suspension of the advertising and expressed its rejection to the advertiser. In terms of methodology, we gathered an ad and three commercials that were described and analyzed based on the reading of Mauss, Goldenberg and Lipovetsky.
\end{abstract}

Keywords: Body. Woman. Advertising. Hope. Regulation.

\section{Introdução}

Em setembro de 2011, a mídia brasileira veiculou uma campanha para a marca de lingerie Hope estrelada pela modelo Gisele Bündchen. A campanha Hope ensina continha um anúncio de revista e três comerciais de televisão intitulados Bati o carro, Estourei o cartão e Mãe vem pra cá. $\mathrm{Na}$ campanha, a garota-propaganda ensinava jogos de sedução às telespectadoras por meio da valorização do corpo feminino trajando lingerie. Hope afirmava que a maneira "correta" de a mulher conversar com o companheiro sobre problemas como o estouro no limite do cartão de crédito, a batida de carro e a visita inesperada da sogra, era trajando apenas lingerie como Gisele Bündchen. O modo "errado" de fazer isso era representado pela modelo vestida de roupas do dia a dia, como vestido e bermuda e blusa. O conceito criativo da campanha se apoiava no texto "você é brasileira, use seu charme", e no slogan "bonita por natureza".

Tal representação da mulher brasileira causou protestos de grupos variados. A campanha criada pela agência Giovanni+DraftFCB tornou-se tema de discussões que permearam as esferas acadêmica, pública e publicitária. Diante da abordagem dos anúncios e das representações exibidas, a Secretaria de Políticas para as Mulheres da Presidência da República pediu ao Conselho de Autorregulamentação Publicitária (Conar) a suspensão dos comerciais e, paralelamente, manifestou ao anunciante seu repúdio ao caráter machista da campanha. Depois de um julgamento interno, o Conar não suspendeu a campanha, mas em 2012 ela voltou ao ar modificada e com outra garota-propaganda.

Sensual mesmo para dar más notícias, G. Bündchen, nessa representação publicitária, mostra em parte como a mulher e seu corpo vêm aparecendo nos produtos da cultura de massa. Anúncios publicitários, revistas femininas, editoriais de revistas de moda são espaços que veiculam imagens da mulher brasileira em larga escala. Comerciais como os dessa campanha são expressão de uma cultura que "naturaliza" o corpo, trazendo-o para a cena como objeto de satisfação das necessidades do gênero masculino. Ao mesmo tempo, reforçam imagens da mulher como aquela que se submete (ou finge submeter-se) para conseguir o que deseja.

Partindo dessa perspectiva, neste artigo temos como objetivo analisar e discutir representações da brasileira como mulher sensual, dotada de beleza "natural", aquela na qual o corpo perderia seu caráter cultural (MAUSS, 1974) e teria destacado seu aspecto "natural". Para isso, em termos metodológicos, descrevemos e analisamos os três comerciais da campanha polêmica, entrelaçando três apelos persuasivos recorrentes na publicidade: o corpo feminino, o apelo sexual e a celebridade como garota-propaganda. Para fundamentar nossa leitura desse corpo feminino, recorremos ao pensamento de Marcel Mauss, para pensar sobre o corpo como cultura; de Miriam Goldenberg, para refletir sobre o corpo como capital na cultura brasileira; e de Gilles Lipovetsky, para discutir a mulher contemporânea no âmbito da cultura de massa.

\section{O sensual corpo feminino: do natural ao naturalizado}

O corpo feminino tem sido tema explorado nos meios de comunicação do país de forma recorrente. Ora é o fim do consumo, aquele a quem é destinada a publicidade, ora é apontado como objeto de consumo. De todo modo, "o corpo nunca foi tão glamourizado, usado, mitificado, massacrado, manipulado, banalizado, estetizado e programado" pela mídia como atualmente (VELLOSO; ROUCHOU; OLIVEIRA, 2009, p.17). 
Nesse contexto, observa-se a "naturalização" do corpo feminino, apresentado como "naturalmente" belo, sensual quando as noções de belo, de charmoso e sensual são construções culturais. Em uma perspectiva antropológica, nenhum corpo é bonito por si só, a leitura cultural de dado grupo social é que vai possibilitar classificar um corpo como belo e outro como feio. Em última instância, um corpo seria "culturalmente" belo.

É possível observar o processo de "naturalização" do corpo em diversas instâncias midiáticas, por exemplo, na exposição de imagens corporais em mensagens publicitárias direcionadas ao público masculino via garotas-propagandas que anunciam mercadorias do segmento de bebidas alcoólicas e de perfumaria. Outros formatos midiáticos também não ficam à margem dessa estratégia: as telenovelas, os programas dominicais de auditório, os programas de entretenimento direcionados ao público jovem. Assistentes de palco, de corpos disciplinados por intervenções plásticas e musculação, dançam adornadas por roupas provocantes, sorriem para as câmeras. Nos incontáveis reality shows transmitidos pela TV por assinatura o foco é para os cuidados com o corpo, nas áreas de beleza, saúde e fitness. E mesmo que se observe a construção cultural desses corpos, o discurso sobre seu "natural" ainda é forte.

Nesse âmbito, é compreensível que o corpo feminino paute cada vez mais as discussões na contemporaneidade, ocupando um lugar de destaque em diversos campos de saberes. Como observou Santaella, "o corpo está em todos os lugares. Comentado, transfigurado, pesquisado, dissecado na filosofia, no pensamento feminista, nos estudos culturais, nas ciências naturais e sociais, nas artes e na literatura" (SANTAELLA, 2004, p.133).

De todo modo, a maneira pela qual a campanha Hope ensina abordou o corpo feminino, como instrumento de convencimento e argumento sobre situações embaraçosas que envolviam dinheiro e família na relação de um casal, provocou um desconforto no âmbito da defesa dos direitos da mulher. O repúdio a tal representação foi fundamentado no fato de que a publicidade promovia o reforço do estereótipo da mulher como objeto sexual do homem, ignorando os avanços na desconstrução de práticas e pensamentos sexistas e apontando para um ética enviesada, interessada, que recorre ao uso do corpo para obter "vantagens pessoais".
A historiadora Mary Del Priore (2011) entende que a história das mulheres passa pela história de seus corpos. Ela pontua o corpo como produto social, cultural e histórico que a sociedade fragmentou e recompôs, regulando seus usos, normas e funções. Del Priore lembra que, desde o desenvolvimento da pílula anticoncepcional para as mulheres, o corpo feminino se revelou para a construção de novos sentidos além do procriar.

A década de 1960, por exemplo, representou uma revolução nos hábitos sexuais das brasileiras, que antes concebiam muitos filhos devido à quase impossibilidade de planejamento nas relações entre o prazer, a subserviência aos maridos e a ausência de anticoncepcionais. Por meio da pílula anticoncepcional, o corpo feminino deixou de servir exclusivamente à procriação e as relações sexuais também se estabeleceram como fonte de prazer e de bem-estar para as mulheres.

A antropóloga Mirian Goldenberg (2006), no artigo "O corpo como capital: para compreender a cultura brasileira", aponta o corpo como elemento básico da construção da identidade nacional. A autora recorre ao conceito de imitação prestigiosa, de Mauss (1974), para explicar a construção cultural do corpo e, no caso do Brasil, a valorização de atributos físicos como forma de construção de uma cultura da sensualidade e do corpo como capital cultural.

Pensar sobre a representação midiática do corpo da mulher na contemporaneidade requer certos cuidados. Segundo Lipovetsky (2000), a mulher contemporânea é bem diferente daquela descrita como o "segundo sexo" dominado e inferiorizado pelos machões, como também da combativa "mulher liberada" do feminismo histórico.

A "primeira mulher" corresponderia a Eva da tradição judaico-cristã como um ser nefasto, tentador e diabólico para o ambiente masculino. A "segunda mulher", a da Idade Média, é aquela espécie de anjo idealizado por sua beleza e qualidades "passivas", pois seus atributos eram usados a partir da vontade dominadora do sexo oposto. Já a "terceira mulher" marca o espaço social a partir da segunda metade do século XX e se institui como uma invenção de si mesma (longe da ideia de origem a partir da costela do homem): ela é "indeterminada" nas palavras de Gilles Lipovetsky (2000).

A "terceira mulher" é um personagem moderno, fruto da revolução sexual e da inserção 
no mercado de trabalho, que desvinculou o sexo da atividade de procriação. No entanto, essa mesma mulher também pode gozar do prazer nas atividades tradicionais, no exercício de seu papel materno, de organizadora da casa e de amante que pode usar de relativa passividade nos jogos de sedução com seu companheiro.

A novidade, então, é que as mulheres parecem possuir agora autonomia e iniciativa no desempenho dos velhos papéis, sem precisar retornar à posição subalterna em relação ao homem ou mesmo à ordem social. A "terceira mulher" inventaria seu próprio destino de acordo com seus desejos internos: ser solteira ou casada, com ou sem filhos, assumir cargos de comando no mercado de trabalho ou assumir o cargos de assistente, relacionar-se sexualmente com reduzido ou amplo número de parceiros. E essas opções não implicariam mais escolher entre a liberdade e a sujeição. Nesse contexto, "o imaginário sexual tornou-se uma gigante estratégia de vendas" (PRIORE, 2011, p. 236).

A mensagem publicitária de Hope tem um objetivo comercial a cumprir em um contexto de enunciadores/coenunciadores e de consumidores de produtos e promessas. Por vezes, encontramos o uso de humor e sexo, como fortes apelos persuasivos. No caso de uma campanha voltada para um segmento de lingerie como a Hope, é ainda mais difícil desvencilhar o produto do anunciante (peças íntimas, calcinha, sutiã) do universo composto por apelos sexuais que envolvem os corpos. Numa análise de imagem sobre a publicidade, Jacques Aumont (2001) preconiza que:

A imagem publicitária, concebida por definição para ser facilmente interpretada (sem o que ela é ineficaz), é também uma das mais sobrecarregadas de todo tipo de códigos culturais. [...] o trabalho dos criadores consiste em fabricar imagens que possam ser lidas com aplicação de diferentes estratégias, segundo o número e a natureza dos códigos mobilizados, e em tornar essas estratégias compatíveis; assim, o espectador mais culto, ou mais "atualizado", captará alusões, citações e metáforas que escaparão a uma leitura mais rudimentar, mas em todos os casos, um significado comum deve estar presente, sob pena de insucesso (AUMONT, 2001, p. 250).
Entretanto, precisamos ressaltar o considerável risco de uma campanha publicitária "engraçadinha” se transformar em um desserviço público, por propagar comportamentos polêmicos em uma sociedade com um profundo ranço machista, em que a violência contra a mulher ainda é uma tônica e em que o acesso a outros meios de informação que os meios de comunicação de massa ainda é uma realidade distante para classes sociais menos abastadas. A campanha Hope ensina perpassa essa lógica, já que seu conceito afirmava que a mulher brasileira é bonita por natureza e que deveria usar seu charme para alcançar seus objetivos. Aqui identifica-se claramente o reforço no discurso de naturalização da beleza e, consequentemente, na ocultação do processo social que permite construir a beleza. Afinal, beleza não é categoria objetiva, não existe por si só, nem é dada a priori, mas é construída no meio social. Diferentes sociedades terão distintos "padrões" de beleza.

Para Martin Lindstrom (2009), entre o sexo e a polêmica, a última tem mais peso no que se refere ao índice de vendas de uma campanha publicitária. $\mathrm{O}$ autor afirma que sexo e beleza não necessariamente vendem produtos. Lindstrom (2009) entende que o sexo na publicidade tem tudo a ver com a satisfação de um desejo e com a construção de sonhos de consumo. Nessa perspectiva mercadológica, ao ver o corpo idealizado de Gisele Bündchen na publicidade de lingerie de Hope, as mulheres traduziriam e interpretariam a mensagem de que aquele corpo representa também o seu corpo, afinal elas também são brasileiras, portanto, "naturalmente" belas e charmosas, de acordo com Hope.

\section{Hope ensina e reforça representações}

A campanha estudada é composta por três comerciais de quinze segundos. Todas as peças apresentavam a modelo Gisele Bündchen como garota-propaganda, representando uma personagem feminina que ensinava às telespectadoras brasileiras a forma "correta" de passar notícias desagradáveis ao parceiro: uma batida de carro, uma visita inesperada da sogra ou um abuso no limite no cartão de crédito. Transcrevemos a sequência de cada comercial, para melhor entendimento sobre o tratamento estereotipado relativo ao uso do corpo feminino. 
A Figura 1 se refere a uma imagem do comercial "Bati o carro". Nele, Gisele Bündchen aparece de vestido branco, mexe com o cabelo aparentando certo desconforto em sua expressão facial e diz: "Amor, bati o carro". Entra na tela o lettering "errado" em cor vermelha. Após efeito de áudio, a modelo reaparece de lingerie vermelha dizendo ao marido: "Amor, deixa eu te falar uma coisa, eu bati seu carro. De novo". Neste momento surge na tela o lettering "certo" também em vermelho. Entra o áudio da assinatura do comercial: "Você é brasileira, use seu charme", seguido do slogan "Hope: bonita por natureza". A luz é rebaixada e Gisele Bündchen desfila de um lado ao outro da tela.

A Figura 2 se refere ao comercial "Mãe vem pra cá”. Nele, Gisele Bündchen surge de vestido bege escuro, estica os braços simulando uma pose infantil e demonstra felicidade, falando: "amor, a mamãe vem morar com a gente". Entra na tela o lettering com o adjetivo "errado" em cor laranja. Depois do efeito de áudio, a modelo volta de lingerie amarela fazendo gesto de boa "surpresa" e anunciando: "Meu amor, sabe quem vem morar com a gente? Mamãe!".
Neste momento entra o lettering "certo" em cor amarela na tela. Como no primeiro comercial, entra o áudio da assinatura do comercial: "Você é brasileira, use seu charme", seguido do slogan "Hope: bonita por natureza". A luz é rebaixada e Gisele Bündchen desfila do lado esquerdo da tela ao lado direito.

$\mathrm{Na}$ terceira figura temos o comercial "Estourei o cartão". Nesse, a modelo aparece de camisa e bermuda e diz: "amor, sabe o teu cartão de crédito? Puf!" Entra na tela o lettering "errado" em cor azul. Efeito de áudio. A modelo reaparece com lingerie de cor azul e diz: "Amor, eu estourei o limite do cartão de crédito! Do seu e do meu!" Neste momento entra o lettering "certo" em azul. Como nos dois comerciais anteriores, entra o áudio da assinatura do comercial: "Você é brasileira, use seu charme", seguido do slogan "Hope: bonita por natureza". No encerramento, a luz é rebaixada e Gisele Bündchen desfila.

Logo após a primeira inserção da campanha, veiculada em 20 de setembro de 2011, os comerciais renderam uma polêmica em torno da

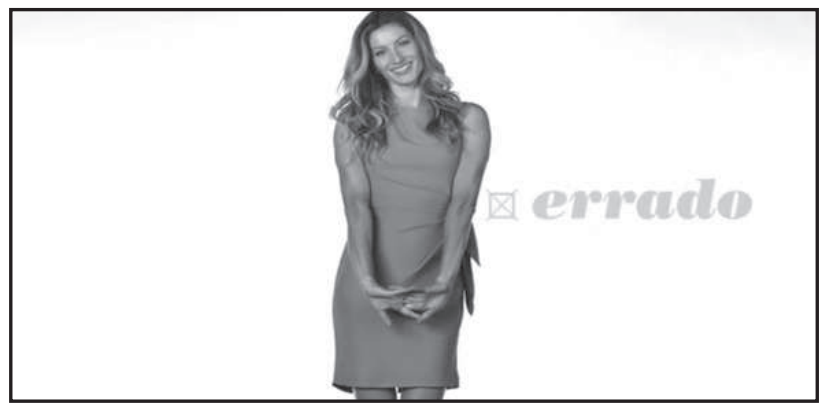

Figura 1 - Comercial "Bati o carro" Fonte: Hope (2011).

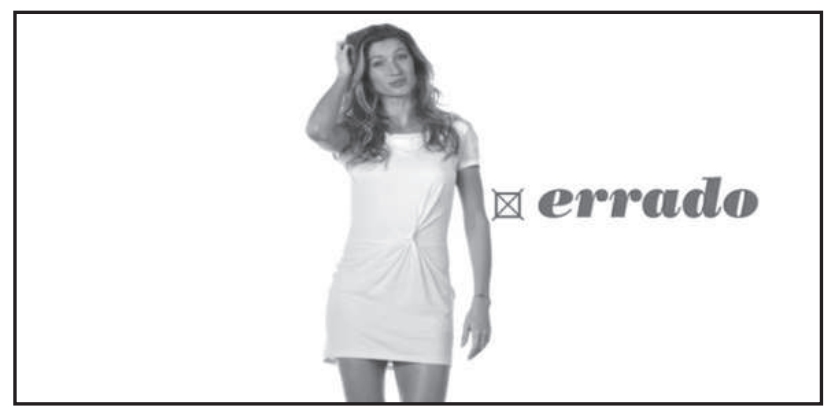

Figura 2 - Comercial "Mãe vem pra cá" Fonte: Hope (2011).
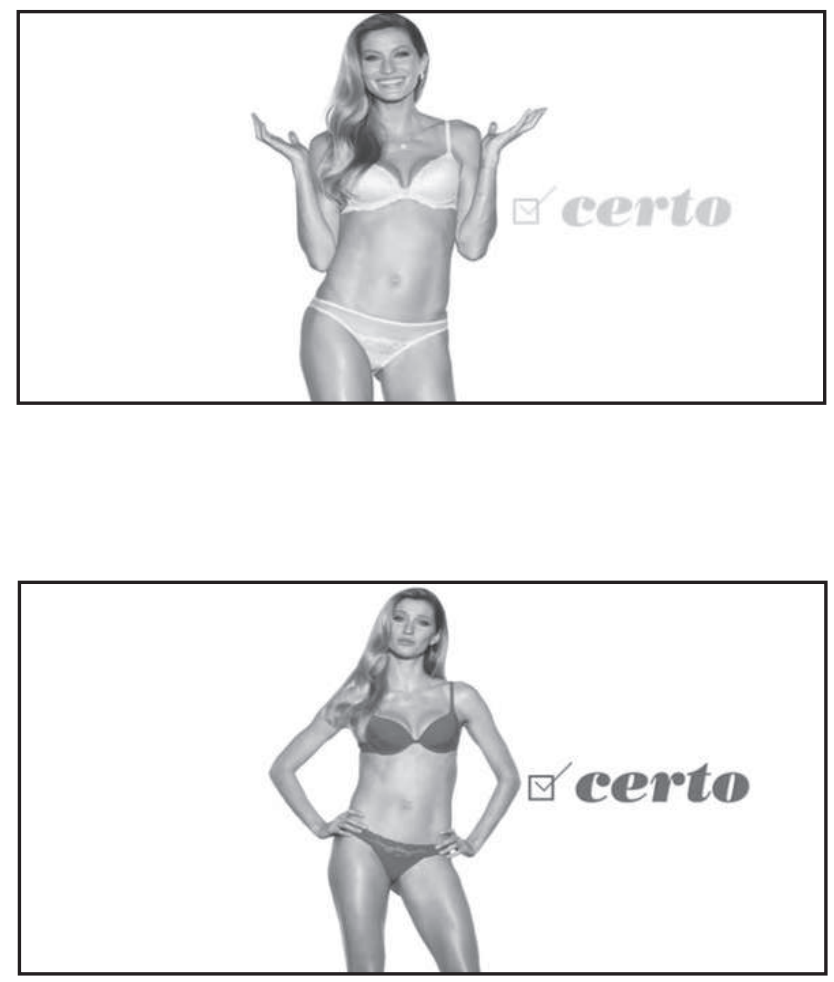
utilização do corpo feminino, da imagem da mulher exposta como objeto. A Secretaria de Políticas para as Mulheres (SPM) - chefiada na ocasião pela ministra Iriny Lopes - pediu a suspensão da publicidade ao Conar com base no Código Brasileiro de Autorregulamentação Publicitária. A ministra também enviou ofício ao diretor da Hope Lingerie, manifestando repúdio à campanha.

Um dos trechos do documento de representação enviado ao Conar explicava a atuação da secretaria em relação aos conteúdos veiculados pelos meios de comunicação de massa:

a Ouvidoria desta Secretaria recebe demandas da população a respeito de programas de televisão, músicas, internet e demais propagandas discriminatórias e sexistas, além de casos de violência doméstica e demais crimes contra as mulheres em todo o país, e que todas elas são encaminhadas para os órgãos competentes para investigação e fiscalização/resolução. E esta tem sido a prática desde sua criação (SECRETARIA DE POLÍTICAS PARA AS MULHERES, Representação ao Conar, 2011).

$\mathrm{Na}$ mesma linha de pensamento, o ofício enviado ao diretor da Hope Lingerie protestava contra a exibição de peças publicitárias com imagens apelativas de mulheres alegando que, além do desrespeito à mulher, tais imagens desrespeitavam também sua inteligência:

A difusão cultural ocorre por distintos meios e na sociedade contemporânea, os meios de comunicação de massa constituem uma via expressa de propagação de padrões culturais. A exposição exagerada e desprovida de conteúdo do corpo feminino,

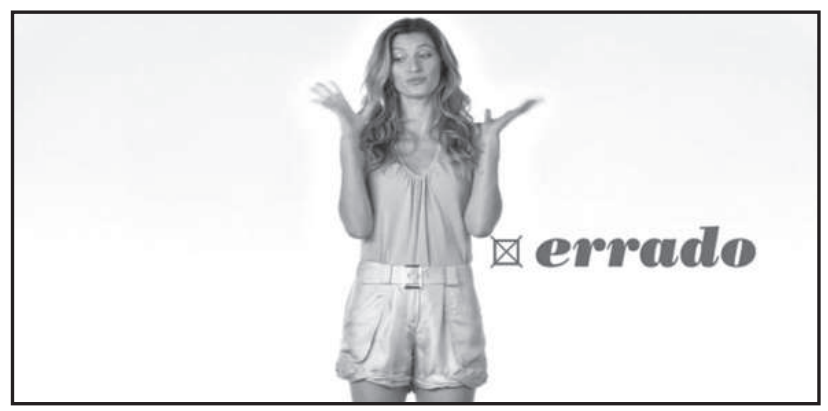

Figura 2 - Comercial "Estourei o cartão" Fonte: Hope (2011). por meio de músicas, imagens e propagandas apelativas é um desrespeito à capacidade intelectual e criativa das mulheres (SECRETARIA, Ofício n.o 185/2011, 2011).

Respondendo às críticas recebidas e se defendendo da acusação de machismo e sexismo, em 28 de setembro de 2011, o anunciante Hope publicou uma nota explicativa na revista voltada para o meio publicitário Meio e Mensagem. Na nota, o anunciante explicava o tom de humor da campanha (e não de preconceito) e recorreu, para isso, à imagem de sua garota-propaganda:

Foi exatamente para evitar que fôssemos analisados sob o viés da subserviência ou dependência financeira da mulher, que utilizamos a modelo Gisele Bündchen, uma das brasileiras mais bem sucedidas internacionalmente. Gisele está ali para evidenciar que todas as situações apresentadas na campanha são brincadeiras, piadas do dia a dia, e em hipótese alguma devem ser tomadas como depreciativas da figura feminina. Seria absurdo se nós, que vivemos da preferência das mulheres, tomássemos qualquer atitude que desvalorizasse nosso público consumidor (HOPE..., 2011).

Atendendo à denúncia encaminhada pela Secretaria de Política para as Mulheres, além de denúncias de mais 40 consumidores, no dia 29 de setembro de 2011, o Conar instaurou um processo ético para investigar o caso do anúncio "Gisele Bündchen - Hope ensina”. Participaram da reunião para avaliar o caso cerca de 20 conselheiros e todos votaram pelo arquivamento do pedido de sustação dos filmes. Eles consideraram que os estereótipos 
presentes na campanha são comuns à sociedade e facilmente identificados por ela, não desmerecendo a condição feminina. Assim, em 13 de outubro, o conselho recomendou o arquivamento do processo e, consequentemente, a campanha não foi retirada do ar.

É interessante observar na avaliação do Conar que se reconhece que ali há a utilização de estereótipos - mesmo de preconceito - mas como isso estaria "enraizado" na cultura brasileira, não haveria problema em ser usado na publicidade. Aqui aparece claramente a publicidade como instância que reforça representações, mesmo as que podem ser consideradas ofensivas à mulher, se tais representações estão difundidas. A publicidade aqui assume uma posição amoral.

A SPM decidiu não recorrer da decisão, uma vez que avaliou que o fato de o Conar ter levado a representação a julgamento em seu Conselho de Ética já significou um importante avanço.

Assim, a visibilidade conquistada pelo protesto foi considerada um aspecto positivo - para os dois lados. Na perspectiva dos direitos da mulher, houve mudanças na continuação da campanha. Mas, na perspectiva empresarial também houve ganho: aumentou a procura por franquias da marca Hope (VEJA, 2011, p. 89).

Em maio de 2012, antes de lançar no mercado o nome da nova garota-propaganda da Hope, o anunciante realizou uma pesquisa em uma rede social (Facebook) com a seguinte pergunta: "quem é a nova cara da Hope?”. O resultado apontou para a projeção de celebridades femininas em função de suas participações nas telenovelas brasileiras. O nome da atriz Juliana Paes foi o mais votado com $37 \%$ da preferência, seguido da também atriz Isis Valverde com $21 \%$ dos votos.

No segundo semestre de 2012, a Juliana Paes assumiu o posto de protagonista da marca, enquanto Gisele Bündchen seguiu à frente da linha Gisele Bündchen Brazilian Intimates, da Hope.

\section{Considerações finais}

Campanhas publicitárias como Hope ensina fazem mais do que simplesmente acionar o consumo de um determinado bem. Elas traduzem concepções e visões de mundo ainda presentes na sociedade brasileira onde o corpo feminino e as emoções são tomados como naturais e espontâneos. Ao mesmo em que naturaliza o corpo e a sensibilidade feminina, a campanha reproduz uma espécie de ethos em que a mulher é concebida como um ser submisso moralmente inferior ao homem, afinal, em todas as situações analisadas a personagem de Gisele solicita ao parceiro algum tipo de autorização mediada por atributos relacionados ao campo da sensualidade. Como se não bastasse isso, pode-se ousar dizer que a campanha flerta com a fronteira perigosa de um outro campo de relações sociais tidas como negativas na estrutura da sociedade ocidental, mas também na brasileira: a prostituição, a venda do corpo para o prazer do outro.

O manifesto contra a campanha Hope ensina contou com apoio de 40 mulheres que enviaram denúncias ao Conar para somar forças junto à SPM e lançar o tema ao debate. Contudo, tal número não foi considerado relevante a ponto de levar à retirada imediata da campanha do ar.

A agência criadora dos comerciais adotou como posicionamento diante deste caso relacionar a imagem da modelo e empresária Gisele Bündchen admirada por sua carreira bem-sucedida-justificando dessa forma que o uso do corpo e da sensualidade como argumento seria apenas uma brincadeira. Não haveria propósito, segundo esse argumento, para a marca nem para a própria celebridade, assumir um personagem submisso ao gênero masculino.

No entanto, é importante refletir sobre alguns pontos que não aparecem na resposta da agência e nem do anunciante: que a equipe de criação da campanha era formada por redatores, diretores de arte e diretores de criação do sexo masculino; que a modelo Gisele Bündchen participou no ano de 2011 de outra campanha publicitária (da Sky) assumindo uma personagem submissa e traída pelo marido; que a modelo não participou da campanha da marca em 2012; e, finalmente, que na continuação da campanha os dizeres "Você é brasileira, use seu charme" foram excluídos.

Assim, na construção do argumento da campanha foram levantadas representações masculinas da mulher brasileira e tais representações foram reforçadas pelos publicitários nos comerciais criados por eles. Para a modelo e seus empresários, tal representação da mulher não pareceu inicialmente ofensiva, mas bem humorada. $\mathrm{Na}$ medida em que uma polêmica poderia atingir a reputação 
da modelo internacional, qualificando-a de submissa ou acusando-a de incentivar mulheres a vender sua sensualidade e beleza para atingir seus objetivos ou esconder seus deslizes, a modelo retirou-se da campanha. Finalmente, em sua continuação, em 2012, a campanha foi modificada.

Os desdobramentos da campanha, após o arquivamento do processo, se deram lentamente até o mês de maio de 2012, quando a marca lançou a atriz Juliana Paes como nova garota-propaganda. A empresa anunciante também optou por transformações no que tange ao apelo textual, principalmente em relação ao conceito criativo da nova campanha publicitária, que passou a adotar a assinatura: "Bonita por Natureza, assim como Juliana Paes e você". A proximidade que a palavra "você" traz para a frase passa a sensação de familiaridade entre a garota-propaganda e a consumidora em potencial. Colocar a atriz e a consumidora em potencial num mesmo degrau deixa a marca também mais próxima do público.

$\mathrm{Na}$ "nova" campanha, a sensualidade continua presente, o corpo feminino também mantém destaque, mas o discurso sobre o que fazer e como usar a sensualidade é retirado. A nova garota-propaganda é representação de sensualidade, tendo interpretado em 2012 Gabriela, série inspirada na obra de Jorge Amado. Enfim, a sensualidade está em cena, mas Hope não ensina mais a usá-la.

\section{Referências}

AUMONT, J. A imagem. São Paulo: Papirus, 2001.

CALCINHA, sutiã e amolação. Veja, Edição n.2237, p.89, 05 out. 2011. Disponivel em: < http://veja.abril. com.br/acervodigital/home.aspx >. Acesso em: Acesso em: 17 nov. 2012.

GOLDENBERG, M. O corpo como capital: para compreender a cultura brasileira. Arquivos em movimento, Rio de Janeiro, v. 2, n. 2, p. 1-9, 2006.

HOPE esclarece comercial com Gisele. Meio e mensagem, 28 set. 2011. Disponível em: <http:// www.meioemensagem.com.br/home/comunicacao/ noticias/2011/09/28/Hope-esclarece-comercial-comGisele.html>. Acesso em: 17 nov. 2012.
LINDSTROM, M. A lógica do consumo: verdades e mentiras sobre por que compramos. Rio de Janeiro: Nova Fronteira, 2009.

LIPOVETSKY, G. A terceira mulher: permanência e revolução do feminino. São Paulo: Companhia das Letras, 2000.

MAUSS, M. As técnicas corporais. In: MAUSS,M. Sociologia e antropologia. São Paulo: Edusp, 1974. v. 2. p. 209-234.

PRIORE, M. D. Histórias íntimas: sexualidade e erotismo na história do Brasil. São Paulo: Planeta do Brasil, 2011.

SANTAELLA, L. Corpo e comunicação: sintoma da cultura. São Paulo: Paulus, 2004.

SECRETARIADEPOLÍTICASPARAASMULHERES. Presidência da República. Ofício n.o 185/2011. Disponível em: < http://www.sepm.gov.br/noticias/documentos-1/ Oficio $\% 20$ no $\% 20185-S P M . P R . p d f>$. Acesso em: 17 nov. 2012.

SECRETARIADEPOLÍTICASPARAASMULHERES. Representação ao Conar. Brasília, 26 set. 2011. Disponível em: <http://www.sepm.gov.br/noticias/ documentos-1/Representacao $\% 20 \mathrm{ao} \% 20$ CONAR. pdf $>$. Acesso em: 17 nov. 2012.

SECRETARIADEPOLÍTICASPARAASMULHERES. SPM pede suspensão da propaganda da Hope ao Conar. 27 set. 2011. Disponível em: < http://www.sepm. gov.br/noticias/ultimas_noticias/2011/09/spm-pede-suspensao-da-propaganda-da-hope-ao-conar $>$. Acesso em: 17 nov. 2012.

VELLOSO, M. P; ROUCHOU,J.;OLIVEIRA, C. Corpo: identidades, memórias e subjetividades. Rio de Janeiro: Mauad, 2009. 